\title{
INTERCALIBRATION OF ENVIRONMENTAL ISOTOPE MEASUREMENTS: THE PROGRAM OF THE INTERNATIONAL ATOMIC ENERGY AGENCY
}

\author{
ROBERTO GONFIANTINI, KAZIMIERZ ROZANSKI and WILLIBALD STICHLER \\ International Atomic Energy Agency, PO Box 100, A-1400 Vienna, Austria
}

ABSTRACT. We briefly present here the environmental isotope intercalibration programs of the International Atomic Energy Agency (IAEA). In fact, the IAEA has implemented two parallel programs during the last 20 years: for stable isotopes of light elements and for a radioactive isotope of hydrogen, tritium. This IAEA activity resulted in the preparation of a number of reference and intercomparison materials of various types, now stored in the Agency and available upon request.

\section{INTRODUCTION}

The Agency's activities in the field of isotope hydrology and geochemistry started ca 30 years ago with the determination of the isotopic composition of precipitation in a worldwide network of stations (in cooperation with the World Meteorological Organization (WMO)). The isotopic analyses (deuterium, tritium, ${ }^{18} \mathrm{O}$ ) were (and are) carried out in the IAEA Isotope Hydrology Laboratory and in a number of associated laboratories. These laboratories thus require accurate intercalibration. This has been a crucial problem since the inception of isotope geochemical investigations in the early 1950s. Thus, IAEA started to organize intercomparison exercises, repeated at regular intervals, with the participation of an increasing number of laboratories. This activity has also led to the preparation and distribution by IAEA of reference samples.

The Agency's current environmental isotope intercalibration program is much wider in scope than initially conceived, and is part of the Analytical Quality Control Service (AQCS) instituted by the IAEA in order to assist laboratories engaged in various fields of scientific research to check the quality of their work. We shall briefly review here the history and characteristics of the program on stable isotopes of light elements and tritium. Until now, the agency has not distributed samples for intercalibration of ${ }^{14} \mathrm{C}$ analyses.

\section{STABLE ISOTOPES}

In 1966, Halevy and Payne (1967) reported at a meeting in Vienna the results of the first stable isotope intercalibration program. Only 12 laboratories took part in this project. Five samples were distributed including NBS-1 and NBS-1A, the first of which Craig (1961) used to define the Standard Mean Ocean Water (SMOW). The results showed reasonably good agreement among most of the participating laboratories, but also the occurrence of systematic deviations for some of them.

Participants at the 1966 meeting recommended, for calibration purposes, the preparation of a water sample with an isotopic composition of the defined SMOW and another water sample depleted in heavy isotopes.

In 1976, Gonfiantini $(1977,1978)$ reported the results of the intercomparison performed on these new samples - Vienna SMOW (V-SMOW) prepared by Harmon Craig, and Standard Light Antarctic Precipitation (SLAP), in addition to NBS-1 and NBS-1A. In 1983, Gonfiantini (1984) reported the results of the intercomparison performed on Greenland Ice Sheet Precipitation (GISP) samples, with intermediate isotopic composition between V-SMOW and SLAP. The agreement was reasonably good but again with a few systematic deviations. It appeared, however, that the spread of values was considerably reduced by normalizing the results, assuming a fixed value for SLAP. For instance, the standard deviation decreased by more than a factor of 2 for GISP (Fig 1). 

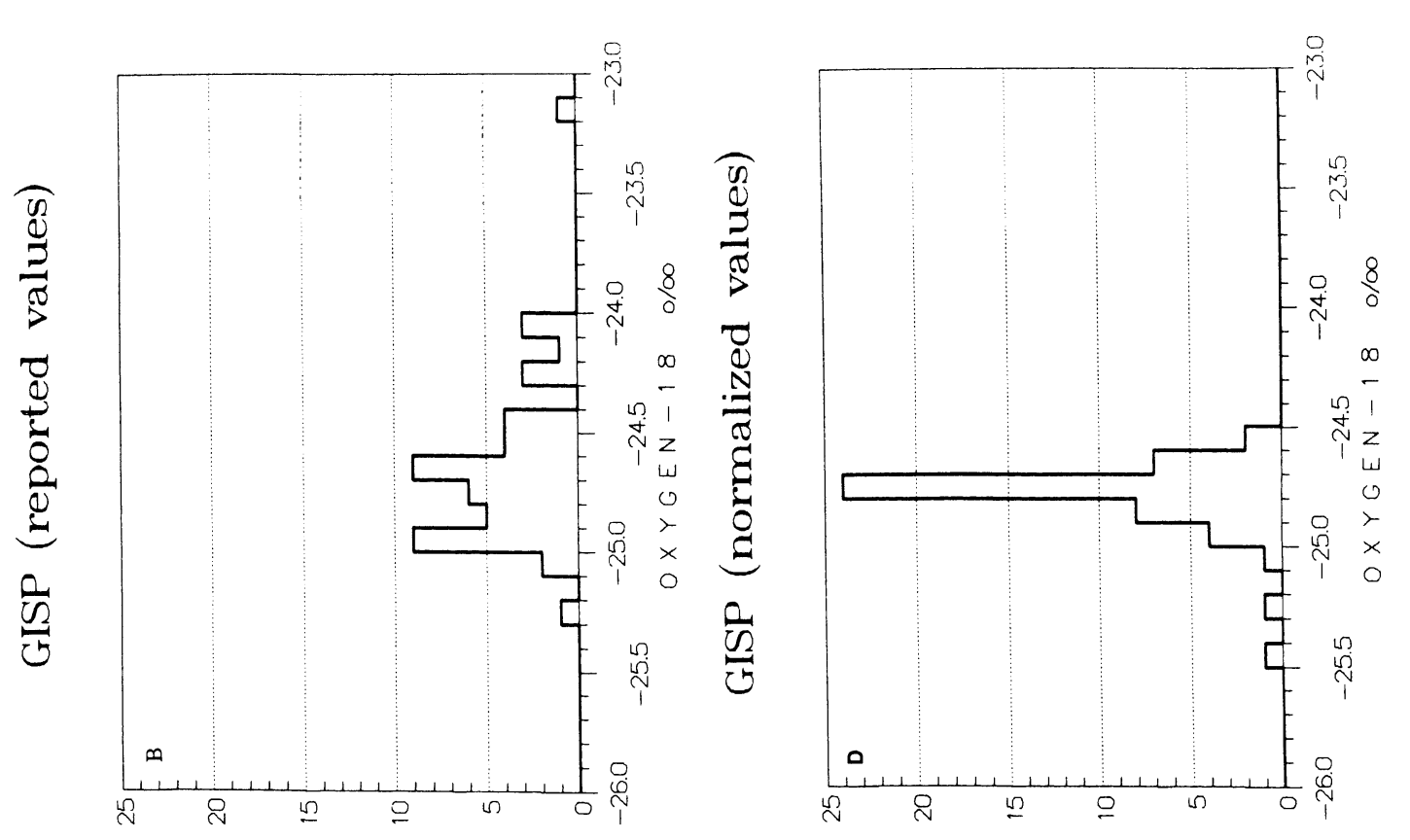

$S \exists \cap 7 \forall \wedge \dashv 0 \quad \forall \exists \boxminus W \cap N$

$5 \exists \cap 7 \forall \wedge \dashv 0 \quad$ y $\exists B W \cap N$

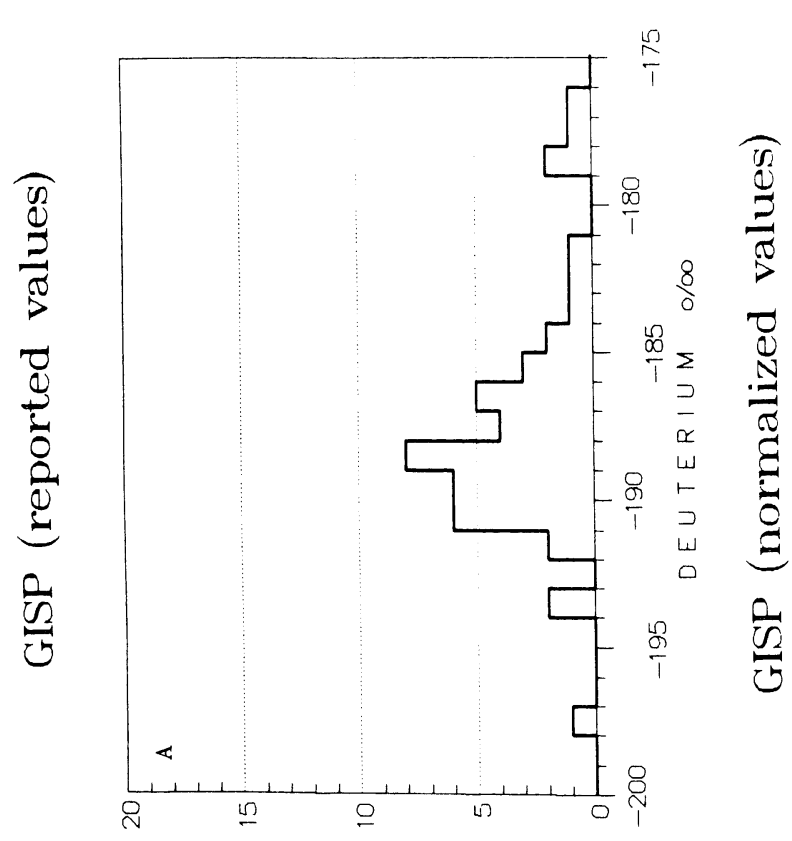

$5 \exists \cap 7 \forall \wedge \dashv 0$ ㅂ $\exists G N \cap N$

$5 \exists \cap 7 \forall \wedge \exists 0 \quad$ y $\exists B \cap N$

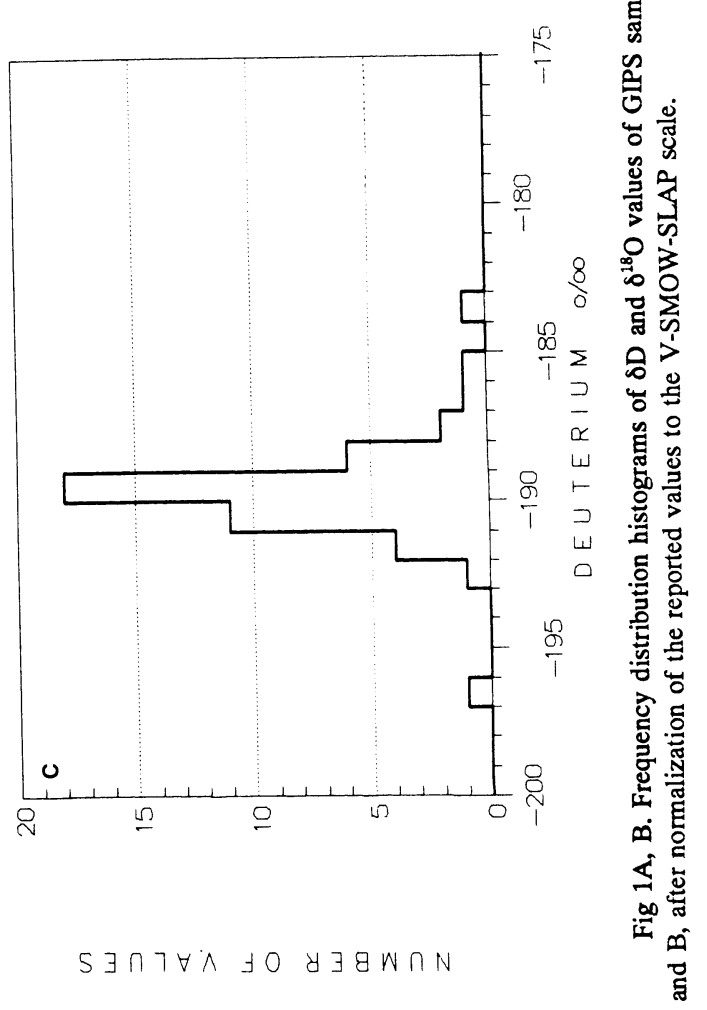


Thus, we agreed to recommend for SLAP the values of $-428 \%$ for deuterium and $-55.5 \%$ for ${ }^{18} \mathrm{O}$ with respect to V-SMOW; in this way, the $\delta$ scales were fixed and normalization eliminated most systematic errors. However, this implied the parallel normalization of the scales and standards used for compounds different from water, as well as that of fractionation factors, in order to make fully consistent all the deuterium and ${ }^{18} \mathrm{O}$ results (Gonfiantini 1984; Hut 1987).

After the 1976 meeting, new intercalibration samples of various types were prepared and distributed, and the results presented at two other meetings held in 1983 and in 1985 . Among the new samples, NBS-19 is particularly important: it consists of calcium carbonate from a marble of unknown origin (possibly Carrara marble), the $\delta$ values of which have been fixed by agreement to $+1.95 \%$ for ${ }^{13} \mathrm{C}$ and $-2.20 \%$ for ${ }^{18} \mathrm{O}$ with respect to $\mathrm{PDB}$ (the latter value corresponds to $+28.63 \%$ vs $\mathrm{V}$-SMOW).

V-SMOW, SLAP and NBS-19 are classified as "Reference Samples," ie, samples used as reference to express measured differences in isotopic ratios. Various specialized laboratories have undertaken the determination of their absolute isotopic ratios, but the values obtained, although of excellent quality, are not certified by the IAEA, nor is their knowledge necessary if results are reported in terms of delta notation.

The Agency now distributes many other samples for intercomparison and intercalibration of stable isotope measurements of all the light elements mainly used in isotope hydrology and geochemistry (Table 1). Unfortunately, the amount available for some of them is very limited.

\section{TABLE 1}

Reference and intercomparison samples for stable isotope measurements distributed by IAEA

\begin{tabular}{|c|c|c|c|}
\hline Code & Isotope & Nature* & Remarks \\
\hline VSMOW & ${ }^{2} \mathrm{H},{ }^{18} \mathrm{O}$ & Water & $\begin{array}{l}\text { Reference standard for } \\
\text { reporting }{ }^{2} \mathrm{H} \text { and }{ }^{18} \mathrm{O} \text { results }\end{array}$ \\
\hline SLAP & ${ }^{2} \mathrm{H},{ }^{18} \mathrm{O}$ & Water & $\begin{array}{l}\delta^{2} \mathrm{H}=-428 \text { and } \delta^{18} \mathrm{O}= \\
-55.5 \% \text { vs VSMOW }\end{array}$ \\
\hline GISP & ${ }^{2} \mathrm{H},{ }^{18} \mathrm{O}$ & Water & \\
\hline NBS- 18 & ${ }^{13} \mathrm{C},{ }^{18} \mathrm{O}$ & $\mathrm{CaCO}_{3}$ & Carbonatite from Norway \\
\hline NBS-19 & ${ }^{13} \mathrm{C},{ }^{18} \mathrm{O}$ & $\mathrm{CaCO}_{3}$ & $\begin{array}{l}\text { Marble; } \delta^{13} \mathrm{C}=+1.95 \text { and } \\
\delta^{18} \mathrm{O}=-2.20 \% \text { vs } \mathrm{PDB}\end{array}$ \\
\hline NBS-22 & ${ }^{13} \mathrm{C}$ & Oil & \\
\hline PEF-1 & ${ }^{13} \mathrm{C},{ }^{2} \mathrm{H}$ & Polyethylene foil & \\
\hline NBS-30 & ${ }^{18} \mathrm{O},{ }^{2} \mathrm{H}$ & Biotite & \\
\hline NBS-28 & ${ }^{18} \mathrm{O}$ & Quartz sand & \\
\hline IAEA N-1 & ${ }^{15} \mathrm{~N}$ & $\left(\mathrm{NH}_{4}\right)_{2} \mathrm{SO}_{4}$ & \\
\hline IAEA N-2 & ${ }^{15} \mathrm{~N}$ & $\left(\mathrm{NH}_{4}\right)_{2} \mathrm{SO}_{4}$ & \\
\hline IAEA N-3 & ${ }^{15} \mathrm{~N}$ & $\mathrm{KNO}_{3}$ & \\
\hline NSVEC & ${ }^{15} \mathrm{~N}$ & Nitrogen gas & \\
\hline NBS- 127 & ${ }^{34} \mathrm{~S},{ }^{18} \mathrm{O}$ & $\mathrm{BaSO}_{4}$ & \\
\hline $\mathrm{NZ}-1$ & ${ }^{34} \mathrm{~S}$ & $\mathrm{Ag}_{2} \mathrm{~S}$ & Being calibrated us CDT \\
\hline
\end{tabular}

*NB - The distribution of other samples has been discontinued for one of the following reasons: 1) there are doubts about isotopic homogeneity; 2) there are doubts about the status of conservation; 3) they are out of stock. 


\section{TRITIUM}

The IAEA has organized four tritium measurement intercomparisons during the last 25 years. The results are available in Cameron (1967), Florkowski, Payne and Sauzay (1970), Taylor (1978) and Hut $(1986 \mathrm{a}, \mathrm{b})$. The basic features of these intercomparisons are in Table 2.

TABLE 2

Basic features of tritium intercomparison programs carried out by IAEA

\begin{tabular}{|c|c|c|}
\hline Year & $\begin{array}{c}\text { Number of participating } \\
\text { laboratories* }\end{array}$ & $\begin{array}{l}\text { Water samples distributed } \\
\text { for intercomparison }\end{array}$ \\
\hline 1965 & 12 (29) & $\begin{array}{l}\text { Sample A: }<100 \mathrm{TU}^{* *} \\
\text { Sample B: } 200-800 \mathrm{TU} \\
\text { Sample C: } 1000-6000 \mathrm{TU}\end{array}$ \\
\hline 1970 & $35 \quad(38)$ & $\begin{array}{l}\text { Sample A: } \sim 10 \mathrm{TU} \\
\text { Sample B: } \sim 50 \mathrm{TU} \\
\text { Sample C: } \sim 250 \mathrm{TU}\end{array}$ \\
\hline 1975 & 41 (79) & $\begin{array}{l}\text { Sample A: }<0.2 \mathrm{TU} \\
\text { Sample B: } 8.37 \pm 0.04 \mathrm{TU} \\
\text { Sample C: } 33.1 \pm 0.1 \mathrm{TU} \\
\text { Sample D: } 678.5 \pm 2.2 \mathrm{TU}\end{array}$ \\
\hline 1985 & $57 \quad(85)$ & $\begin{array}{l}\text { Sample A: }<0.2 \mathrm{TU} \\
\text { Sample B: } 5.94 \pm 0.03 \mathrm{TU} \\
\text { Sample C: } 25.66 \pm 0.13 \mathrm{TU} \\
\text { Sample D: } 100.2 \pm 0.5 \mathrm{TU}\end{array}$ \\
\hline
\end{tabular}

* Numbers in parentheses in the second column indicate the number of identified active laboratories to which the announcement was sent.

**1 $1 \mathrm{TU}=1$ tritium unit, corresponding to $\mathrm{a}^{3} \mathrm{H} /{ }^{1} \mathrm{H}$ ratio of $10^{-18}$

In each intercomparison exercise, we distributed a set of water samples covering the actual range of environmental tritium concentration. For the first two intercomparisons, the tritium concentration of samples was known only approximately. The results were published with full identification of the participating laboratories.

For the two more recent exercises we established the tritium activity by high accuracy gravimetric dilution of the tritium standard NBS 4926. We informed participating laboratories of the approximate concentration values and requested detailed information on measurement techniques together with the results. The results were reported anonymously.

Figure 2 summarizes the results of the last intercomparison carried out in 1985 . The conclusion drawn from this exercise is that the situation within the "tritium community" is still far from being satisfactory. Only $38 \%$ of the laboratories produced good results for all four samples distributed and $18 \%$ for three samples; $16 \%$ measured correctly two samples, and another $16 \%$ only one; finally, $12 \%$ of the laboratories did not produce good results on any of the samples distributed. 

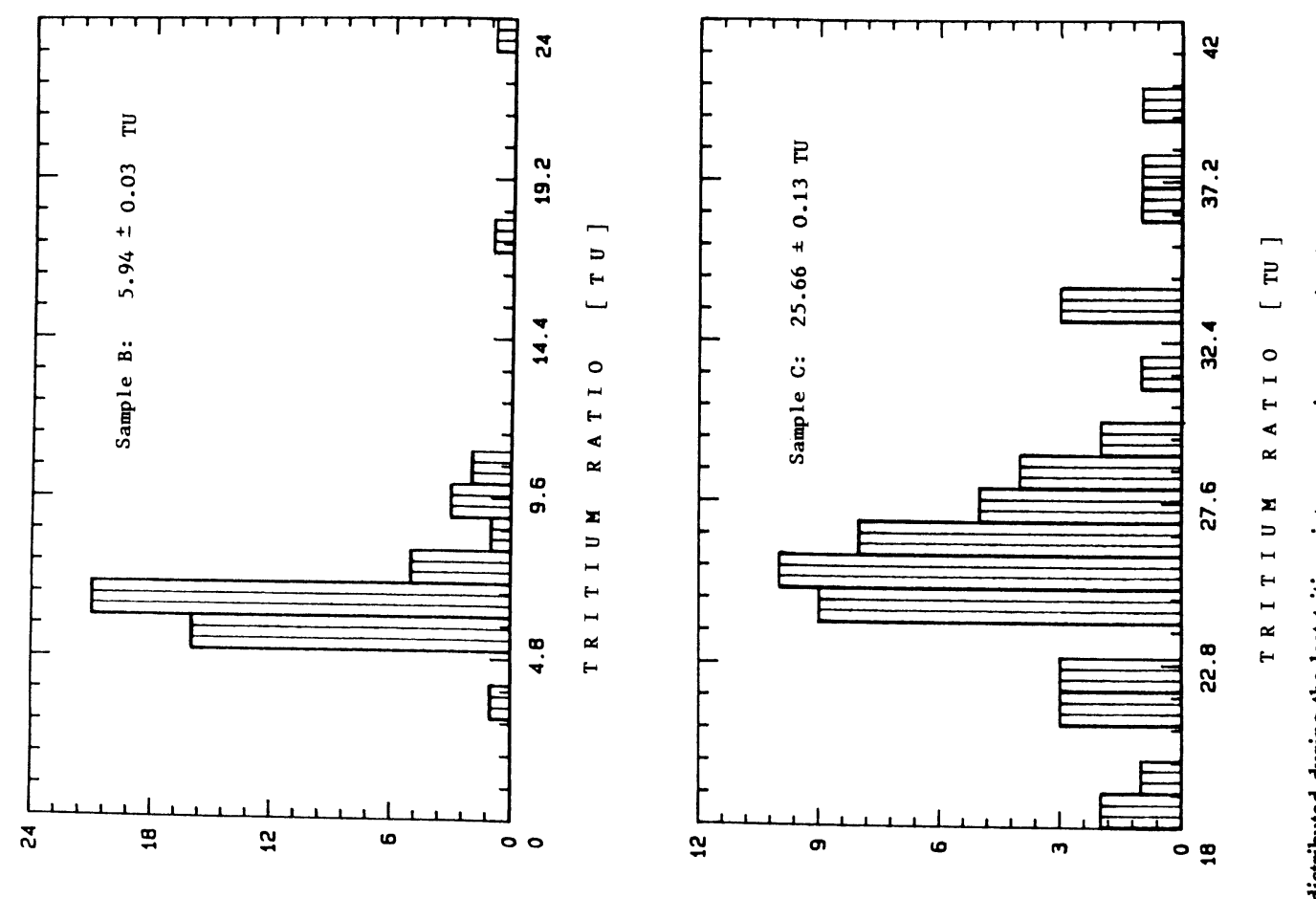

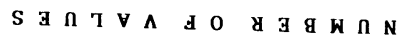
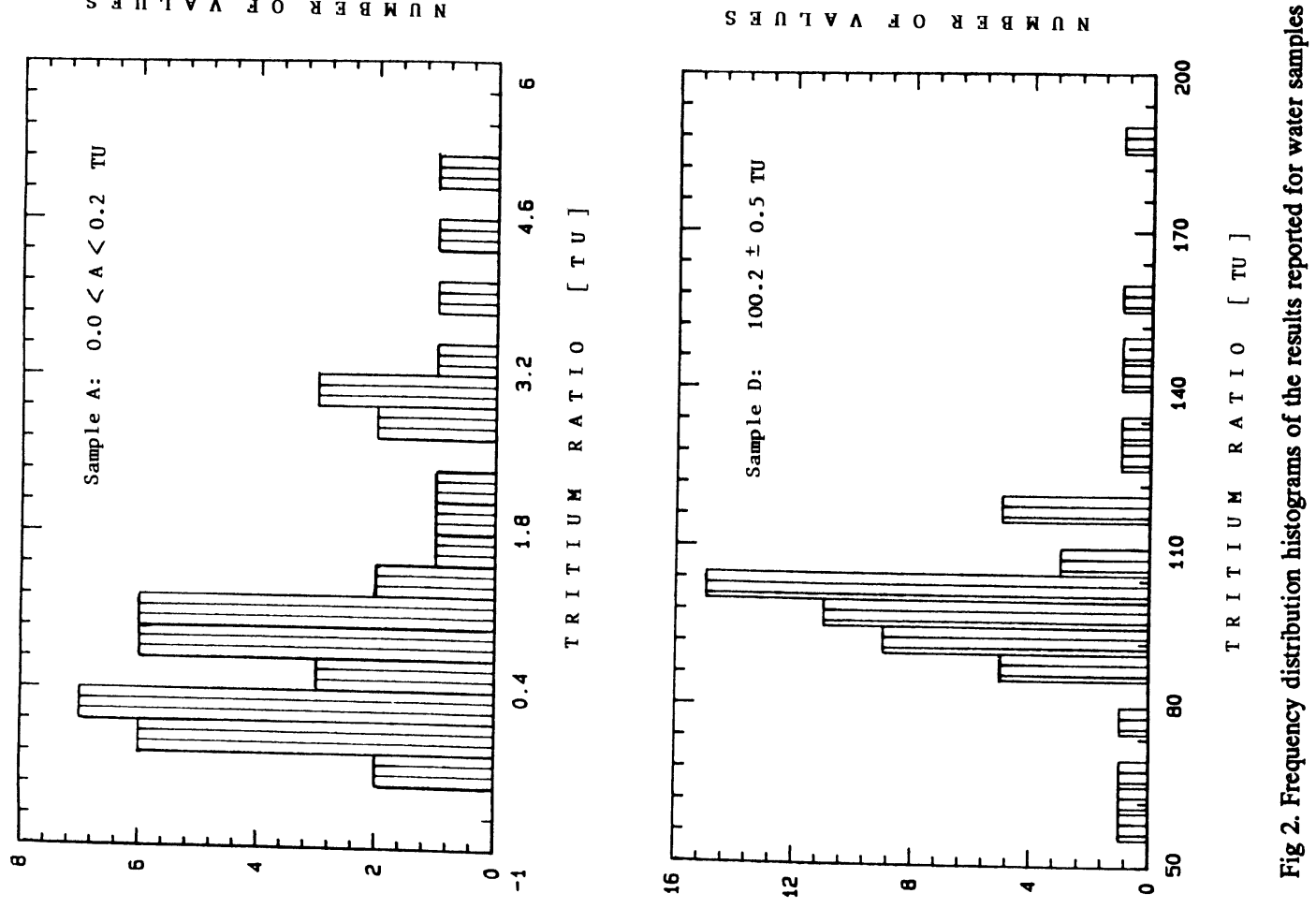

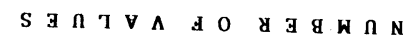

S $3 \cap T \forall \Lambda$ d 0 y 


\section{THE IAEA APPROACH TO THE INTERCOMPARISON OF MEASUREMENTS}

Participation in the IAEA intercomparison exercises is voluntary. However, leading laboratories of recognized experience and quality are usually requested to participate (and also to prepare intercomparison samples). The results are discussed in meetings of invited experts (but open in principle to everybody), and the decisions and recommendations are usually accepted by the scientific community.

Most laboratories applying environmental isotopes in geochemistry, hydrology, agriculture, plant physiology, life sciences, environmental studies, etc, have participated in the Agency's intercomparison exercises. These are considered unique opportunities to check the agreement of the measurements performed with those of other laboratories, to discover the occurrence of errors and systematic deviations, and eventually to try to correct them. Thus, they constitute a continual incentive to improve the quality of the measurements. In conclusion, we are convinced that participation in such exercises is considered not only useful but necessary in order to prove before the scientific community the quality and reliability of isotopic analyses.

\section{REFERENCES}

Cameron, JF 1967 Survey of systems for concentration and low background counting of tritium in water. In Radioactive dating and methods of low-level counting. IAEA, Vienna: 543-573.

Craig, H 1961 Standard for reporting concentrations of deuterium and oxygen-18 in natural waters. Science 133: 1833-1834.

Florkowski, T, Payne, BR and Sauzay, G 1970 Interlaboratory comparison of analysis of tritium in natural waters. Internatl Jour Applied Rad and Isotopes 21: 453-458.

Gonfiantini, R 1977 Report on a consultants' meeting on stable isotope standards and intercalibration in hydrology and geochemistry (Vienna, 8-10 Sept 1976). IAEA, Vienna.

1978 Standards for stable isotope measurements in natural compounds. Nature 271: 534-536.

1984 Report on an advisory group meeting on stable isotope reference samples for geochemical and hydrological investigations (Vienna, 19-21 Sept 1983). IAEA, Vienna.

Halevy, E and Payne, BR 1967 Deuterium and oxygen-18 in natural waters: Analyses compared. Science 156: 669.

Hut, G 1986a Low-level tritium counting facilities: A survey. Nucl Instruments \& Methods B17: 490-492.

1986b Intercomparison of low-level tritium measurements in water. IAEA Rept, Vienna.

1987 Report on a consultants' group meeting on stable isotope reference samples for geochemical and hydrological investigations (Vienna, 16-18 Sept 1985). IAEA, Vienna.

Taylor, CB 1978 Interlaboratory comparison of low-level tritium measurements in water. Internatl Jour Appl Radiation Isotopes 29: 39-48. 